In response to the question of whether the inclusion of behavioural criteria in the definition of 'mental impairment/severe mental impairment' protected the mentally handicapped, 23 per cent replied 'yes' and 58 per cent, 'no'; 19 per cent were non-committal. When asked about wishes for the changes in the definitions, 51 consultants gave individual responses. Fifty-three per cent suggested the inclusion of a clause along the lines 'protection against exploitation of mentally handicapped person and protection against danger to self' in a modified definition. Twenty-one per cent did not wish any change; 14 per cent preferred removal of behavioural criteria from the definition; about four respondents wanted mild or borderline cases of mental handicap taken out of mental handicap legislation. Others wanted 'mental handicap' to be taken out of mental health legislation, redefining the categories according to need for treatment, rehabilitation, social reasons, etc.

The survey has focused on the controversial definition and criteria affecting some of the mentally handicapped people. Hopefully, in the near future, some of these serious weaknesses in an otherwise very humane, progressive and popular piece of mental health legislation, will be rectified, perhaps by emulating the 1983 Amendments of the Scottish Mental Health Act, with particular reference to 'mental handicap' and 'mental impairment'.

Hensol Hospital

T. HARI SINGH

Pontyclun, Mid-Glamorgan

\section{Repatriation of mentally handicapped people}

DeAr Sirs

I felt that our experiences might be of interest to other readers.

Gloucestershire, which historically has had no long-stay mental handicap facilities within the county, has gradually been building up community services and units. We still have 200 persons with origins in the county who are placed in the Bristol mental handicap hospitals.

Two hundred next-of-kin of these people were circulated with a letter asking their opinions on repatriation, if we were to provide a small community unit in their locality. Of the 200 letters sent out, replies were only received from 47 ( 23.5 per cent). Of the 47 that replied, 19 were interested in repatriation; 23 expressed a desire for their relatives to remain in the same place, and not to be repatriated; and five expressed interest in visiting existing units, but tended to indicate a somewhat negative response.

The exercise shows the lack of concern of many of the next-of-kin of mentally handicapped people in hospital. It is also of interest that only 19 out of 200 were immediately positive about repatriation. This may reflect our previous policy of using the first 120 beds which we provided in small community units for repatriating people who had relatives that had maintained a good contact.

DAvid N. WILSON

Coney Hill Hospital

Coney Hill, Gloucester

\section{Clomipramine Challenge Test}

DeAR Sirs

Clomipramine has been demonstrated over the years as an effective antidepressant with a particular predilection for the treatment of phobic and obsessional disorders. The results of numerous clinical trials have been extensively documented and references would be gladly supplied.

To use an efficient drug for purposes other than those for which it was originally intended may sometimes produce surprising results.

In the so-called 'diagnostic test' referrred to by $\mathrm{Dr}$ Holmshaw (Bulletin, April 1984, 8, 76), i.e. to prove a diagnosis which should have been made by efficient history taking in any case and by a method which produces acutely adverse alternative symptoms, is naive, if not bizarre, and cannot be justified in any circumstances.

D. WAXMAN

17 Upper Wimpole Street

London $W I$

\section{Saskatchewan's Secure Unit}

\section{DeAr Sirs}

In response to $\mathrm{Dr} M$. Livingston's description of the Regional Psychiatric Centre (Prairies) (Bulletin, August $1984,8,155-56$ ), I would like to add a few points of clarification and comparison. The three Regional Psychiatric Centres, serving respectively the Pacific, Prairies and Ontario Regions of Canada, offer the highest degree of security available in Canada for the treatment of mentally disordered offenders, and in this respect are comparable to the English Special Hospitals. All the Centres operate as institutions within the Correctional Service of Canada and are classified as maximum security penitentiaries, as well as psychiatric treatment facilities. 'The total separation of security and therapeutic roles', indicated in Dr Livingston's article, evolves directly from the penitentiary background of our institutions, in that orthodox Correctional Officers maintain perimeter and internal security, leaving primary patient care and management to be provided by our nursing and clinical staff.

Unlike the English Special Hospitals, where nursing staff often appear to suffer from a marked intrapersonal conflict of roles, between being a guard on the one hand and a therapist on the other, nursing staff at our Centres are able to view themselves clearly as primarily therapists. The advantages of this demarcation of respective roles are, however, sometimes offset by interdisciplinary rivalry between therapeutic and security staff, stemming from their differing philosophies and background.

The balance between therapeutic and security considerations is both an important and problematic area in the management of mentally disordered offenders, to which Canada has adopted a significantly different approach than that of the United Kingdom.

Regional Psychiatric Centre (Prairies)

C. M. GREEN 